SBN : 978.1.60805.802.

Rural Lifestyles, Community Well-being and Social Change

Lessons from Country Australia for Global Citizens

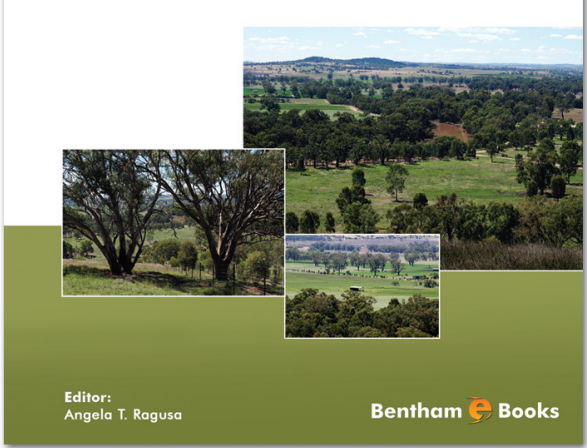

Editor:

Angela T. Ragusa Charles Sturt University

Australia

\title{
Rural Lifestyles, Community Well-Being and Social Change: Lessons from Country Australia for Global Gitizens
}

\section{Ww'henthamseience.com/chooks/9781608058020}

\section{About the ebook}

This edited eBook is a collection of articles that explores 'rural realities' of country life in Australia for global audiences interested in rurality, health and well-being. By transcending disciplinary-specific boundaries, this multi-disciplinary book not only presents contemporary challenges, but also equips readers with evidence-based knowledge to improve resilience in communities and individuals facing key issues such as aging, depression, disability, environmental degradation, limited service delivery and social isolation.

\section{Contents}

Who Owns the Landscape; and is there a Right to a View?

The Urban Push for Environmental Amenity: The Impact of Lifestyle Migration on Local Housing Markets and Communities

Social and Economic Change in Rural Communities: The Lachlan Region of New South Wales Between the 1920s and 1940s

- Resettling Refugees in Rural Areas: Africans, Burmese, Bhutanese and Afghans in the Riverina NSW, Australia

The Impact of Rurality on Depression in Rural Australia: Socio- Cultural Reflections for Social Change

Australian Mental Health Nursing: The Challenges of Working in Rural and Remote Communities

For Advertising Inquiries: Contact: marketing@benthamscience.org 